\title{
On the Philips Recall and the Professionalism of Dental Sleep Medicine
}

Jean-François Masse, DMD, MSc, FACD, Diplomate, ABDSM

Editor-in-Chief Journal of Dental Sleep Medicine

Universite Laval, Quebec City, Quebec, Canada

On June $14^{\text {th }}$, Philips announced the recall of 3 to 4 million continuous positive airway pressure (CPAPs) and Bilevel PAP because of potential health problems with the sound abatement foam used in some of their devices. ${ }^{1}$ Potential problems are many, ranging from skin irritation to toxic carcinogenic affects.

Considering that in 2020, the complaint rate related the sound abatement was a low $0.03 \%$, the action taken by the multinational company seems disproportionally strong, unless it sees a major health threat for the future with potential legal concerns. From what one can read on the Philips website, I find it very offensive that the recall was only issued for the U.S., as if the rest of the world did not deserve the same protection.

The financial impact of such as massive recall will be devastating for Philips for years to come and may also influence public perception of safety of their other health products. We can surmise that such a recall, albeit preventive, seems a business and legal decision. It is striking that such a company does not consider their partners - our patients and our medical colleagues - as their first priority.

I do hope that other CPAP manufacturers will review their equipment; all the more important if they are using similarly 'at risk' components in their products. As a sidenote, Philips is also now discouraging the use of ozone-related cleaning products as the manufacturer has determined that the sound abatement foam may degrade when such cleaning products are used.

The situation raises a few questions. Does Philips have the responsibility to find an alternative solution, since the health of millions of individuals with sleepdisordered breathing may be jeopardized? This is urgent since Philips is advising to most of its USA CPAP and Bilevel PAP customers to stop using their device immediately and to contact their physicians. What options are left for the patient and sleep physician? It will be very interesting to see if otherwise reluctant sleep physicians will begin to offer dental appliances.

It also seems somewhat unprofessional to leave the sleep medicine community stuck with only the option to simply tell their patients to stop using their CPAP and to stop prescribing that specific CPAP therapy. There are major human, social, health and legal hazards associated with Philips' decision. Furthermore, it is not advisable for any company or therapeutic partners to advise patients to buy a new CPAP- this could also (understandably) anger patients.

For those of us in dental sleep medicine, we need to highlight our professional and ethical competencies in providing oral appliance therapy as an alternative. It is possible, not to say probable, that many sleep physicians will direct some of their patients to use oral appliances. Being dental sleep medicine experts, we should guide patients toward the best options, and especially consider oral appliance design. Furthermore, since oral appliances do not work for everyone, use of bi or tri-therapy may be recommended by their sleep physician (e.g., sleep positioning device, other CPAP brand, cognitive and behavioral therapy, emerging medication to maintain muscle tone and other to reduce sleep arousal sensitivity).

While Philips has the responsibility to find a solution, the health of individuals with sleep-disordered breathing may be jeopardized. Additionally, this process could take some time as we are talking about a 3 to 4 million PAP recall.

Furthermore, another major concern - other CPAP manufacturers should let the public know ASAP if their CPAP may pose similar risks. We should not have to wait for the FDA to force such actions. Only time will tell if other companies will have similar recalls as well.

The AADSM has been following the situation closely as we have received reports and resources from the organization. I believe it has chosen the right approach at this time in teaming up with the AASM. The industry has also been supportive, realizing that oral appliances can be valuable. It is now our role, as providers of dental sleep medicine, to demonstrate our professionalism and sleep expertise to both patients and health decision makers.

\section{CITATION}

Masse, JF. On the Philips recall and the professionalism of dental sleep medicine. J Dent Sleep Med. 2021;8(3) 


\section{REFERENCES}

1. Medical device recall notification (U.S. only) / field safety notice (international markets). Phillips Respironics. April 26, 2021. Accessed July 6 , 2021. https://www.usa.philips.com/healthcare/e/sleep/communications/s rc-update
SUBMISSION AND CORRESPONDENCE INFORMATION

\section{Submitted in final revised form July 3, 2021.}

Address correspondence to: Jean-François Masse, DDS, MSc, FACD, D.ABDSM, Professor, Universite Laval, 2780 Masson \#200, Quebec City, QC, G1P 1J6, Canada; Tel: 418871-1447; Fax: 418-871-4983; Email: jean-francois.masse@fmd.ulaval.ca 